\title{
New experimental model of exposure to environmental tobacco smoke ${ }^{1}$
}

\author{
Marcus Vinicius Henriques Brito ${ }^{\mathrm{I}}$, Edson Yuzur Yasojima ${ }^{\mathrm{II}}$, Edvaldo Lima Silveira ${ }^{\mathrm{III}}$, Vitor Nagai Yamaki ${ }^{\mathrm{IV}}$, Renan Kleber \\ Costa Teixeira $^{\text {IV }}$, Daniel Haber Feijón ${ }^{\text {, }}$, Thiago Barbosa Gonçalves ${ }^{\text {IV }}$ \\ IPhD, Full Professor, Head, Department of Integrate Health, Medical School, Para State University (UEPA), Brazil. Conception and design of the study, \\ interpretation of data, critical revision. \\ IIPhD, Associate Professor, Medical School, UFPA, Belem-PA, Brazil. Manuscript writing, critical revision.

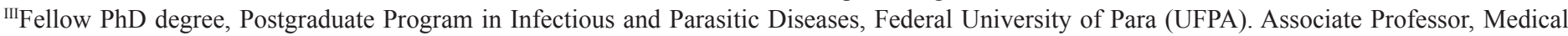 \\ School, UEPA, Belem-PA, Brazil. Histological analysis.

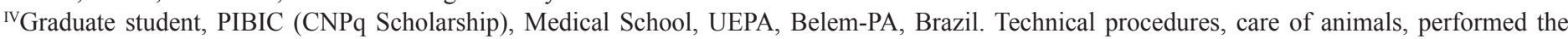 \\ passive smoke and biochemistry analysis.
}

\begin{abstract}
PURPOSE: To describe a new model to passive smoking for rodents.

METHODS: Twenty rats were distributed into two study groups $(\mathrm{N}=10)$ : control group $(\mathrm{CG})$, that was not exposed to tobacco smoke and used as normal standard for biochemical and histological analysis; Experimental Group (EG), that Animals were exposed to the passive smoking; Euthanasia was performed after 14 days of exposure. The serum level of nicotine and histological analysis were performed.

RESULTS: There was a statistical difference on the nicotine serum levels between Experimental and Control group, with level of 286 \pm 23 nanograma/mL in the EG and undetectable on $\mathrm{CG}(\mathrm{p}<0.01)$. The histological study suggested the model efficacy producing alveolar destruction and emphysema in the EG compared with the insignificant lesions in the CG's lung.

CONCLUSION: The model of exposure to environmental tobacco smoke for rodents induced easily the changes related to secondhand smoke.
\end{abstract}

Key words: Lung Diseases. Smoke Inhalation Injury. Rats. 


\section{Introduction}

Smoking is the most important preventable risk factor of many diseases, including coronary diseases, chronic obstructive pulmonary disease and lung cancer. Therefore, nonsmokers are also exposed for these malignant effects of tobacco by exposure to environmental tobacco smoke (ETS). The evidence of this link has appeared since 1986, however, it remains actual until the present day $^{1,2}$.

There is high evidence that exposure to ETS reduces exercise capability is one of the landmarks of acute compromises to the coronary circulation ${ }^{1,2}$. This commitment stems of an increases aggregation of blood platelet, an important step in the genesis of atherosclerosis. Others maleficent effects of passive smoke are the exposure to carcinogenic agents (ex: benzopyrene), increased production of reactive oxygen species (ROS) and necrosis of tissues ${ }^{3,4}$.

Animal models are used as an intermediate step between laboratory studies and trial in humans ${ }^{5}$. Although, there is a limited number of published studies in experimental models of cigarette smoke intoxication and there is not a standard model of this purpose ${ }^{6}$. The differences between models are the inaccurate way to measure the concentration of cigarette smoke, the use of different types of inhalation chambers and the high cost of the models described. The main of this study is to purpose a new model of passive smoking for rodents with low cost and easy confection? ${ }^{7}$.

\section{Methods}

This project was approved by the Ethics Committee in the Use of Animals of the State University of Para (UEPA), protocol 22/12. Twenty male Wistar rats (Rattus norvegicus) were used, weighing between 210 - 250 grams, provided from the Animal Colony of the Experimental Surgery Laboratory of UEPA, kept in a controlled environment, with food and water ad libitum. The animals were randomized distributed into two groups, with 10 animals each:

-Control Group (CG): The animals were used as normal standard for biochemical and histological analysis;

-Experimental Group (EG): Animals were exposed to passive smoking.

\section{Design of the model}

This new model is made of six components ${ }^{8}$ : air compressor (Vigor-Ar ${ }^{\circledR} 110$ volts), conduction pipe, cylindrical inhalation chambers (radius: $9 \mathrm{~cm}$; length: $16 \mathrm{~cm}$; cover with holes), cigarette, compartment of ash storage and a wooden support (Figure 1).

The conduction pipe is first connected to the air compressor that makes a constant flow of air in the filter of cigarette that is positioned inside the chamber inhalation protected for a compartment of ash storage.

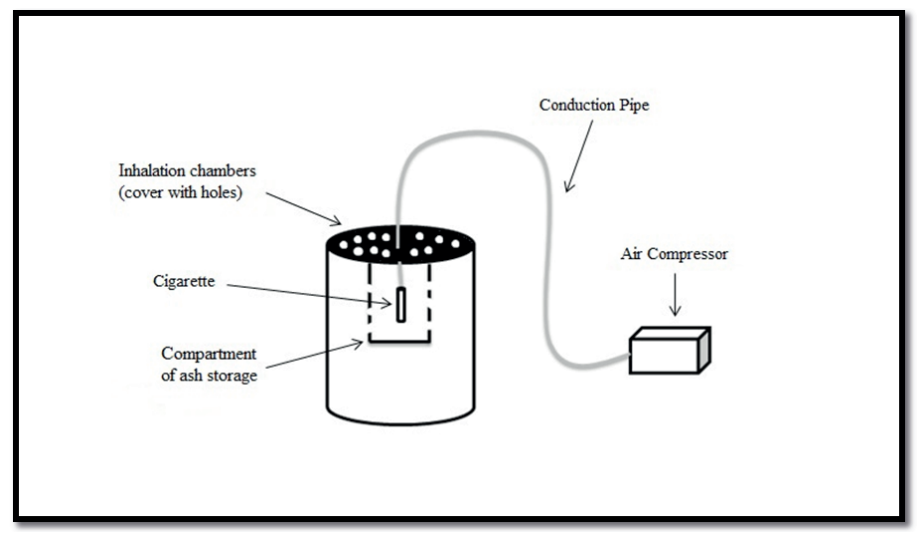

FIGURE 1 - Front view of the dispositive, showing the cover with holes and the cigarette linked.

For the simulate a model of passive smoke the animals are first placed inside the chamber, in the next step the cigarette is lighten, connected in the distal portion of the connection pipe and protected for a compartment of ash storage to prevent burn in animals 'skin and to avoid asphyxia were made holes in the cover of the chamber to leac the part of the smoke produced (Figure 2). Each cigarette produces, nearly, 10-15 min of smoke. After that, the procedure is repeated and the all the animals received two cigarettes per day.

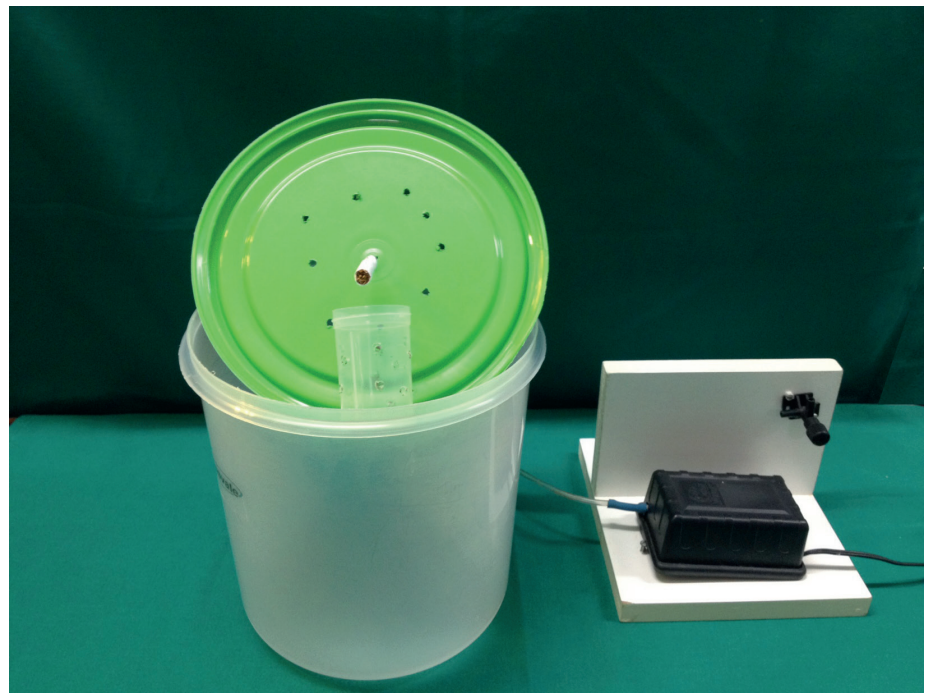

FIGURE 2 - Equipment used to exposure the rats for passive smoke. 


\section{Tobacco smoke exposure}

The passive smoking was realized by placing the animals one by one in the simulator of smoke inhalation always at the same time of the day (15h) being held burning two cigarettes per day per animal for 14 days. The animals were kept in individual cages throughout the remainder of the study.

\section{Biochemical and morphological study}

On the $15^{\text {th }}$ day of experiment was realized the animals' euthanasia, and was collect the lung of the animal and $5 \mathrm{ml}$ of blood to measure the plasma levels of nicotine. The organs collected were stored in $10 \%$ buffered formaldehyde and used for histopathological analysis by means of hematoxylin and eosin.

It was analyzed in the lung ${ }^{9}$ the presence of parenchymal infiltration, fibrosis, necrosis, vascular congestion, thrombosis, inflammatory infiltrate and emphysematous changes were analyzed by a semi-quantitative scale: 0 - absent, 1 - mild, 2 moderate, 3 - severe.

\section{Statistical analysis}

T student test was used to compare the biochemical results and the Mann-Whitney U test to compare the histopathological results. Was adopted a significance level of $5 \%$ to reject the null hypothesis.

\section{Results}

During the procedure no animal died or had lung infection. The mean serum levels of nicotine of the group CG were undetectable by the test but the levels of group GE were $286 \pm 23$ nanograma $/ \mathrm{mL}$, there was a statistical difference $(\mathrm{p}<0.01)$.

The Table 1 shows the data from all histopathological examinations, all criteria analyzed have statistical difference between the groups $(\mathrm{p}<0.01)$. The criteria most frequently found in the experimental group were parenchymal infiltration, vascular congestion and score of inflammatory cells; characteristics of acute inflammation. The Figure 3 shows a comparison of the groups.
TABLE 1 - Histopathological examination data according the group.

\begin{tabular}{cccc} 
Histopathological & $\begin{array}{c}\text { Control } \\
\text { group }\end{array}$ & $\begin{array}{c}\text { Experimental } \\
\text { group }\end{array}$ & p value* \\
\hline $\begin{array}{c}\text { Parenchymal } \\
\text { infiltration }\end{array}$ & $0.70 \pm 0.67$ & $2.30 \pm 0.48$ & 0.0004 \\
Fibrosis & $0.00 \pm 0.00$ & $0.60 \pm 0.51$ & 0.0233 \\
Necrosis & $0.00 \pm 0.00$ & $1.80 \pm 0.63$ & $<0.0001$ \\
& $0.60 \pm 0.69$ & $2.50 \pm 0.70$ & 0.0006 \\
Vascular congestion & $0.00 \pm 0.00$ & $0.90 \pm 0.56$ & 0.0025 \\
Thrombosis & & & \\
& & & \\
Inflammatory cells & $0.80 \pm 0.78$ & $2.80 \pm 0.42$ & 0.0003 \\
Emphysematous & $0.00 \pm 0.00$ & $1.40 \pm 0.51$ & 0.0002 \\
changes & & &
\end{tabular}

Source: Protocol search

*Comparison between control and experimental group (Mann-Whitney U test)

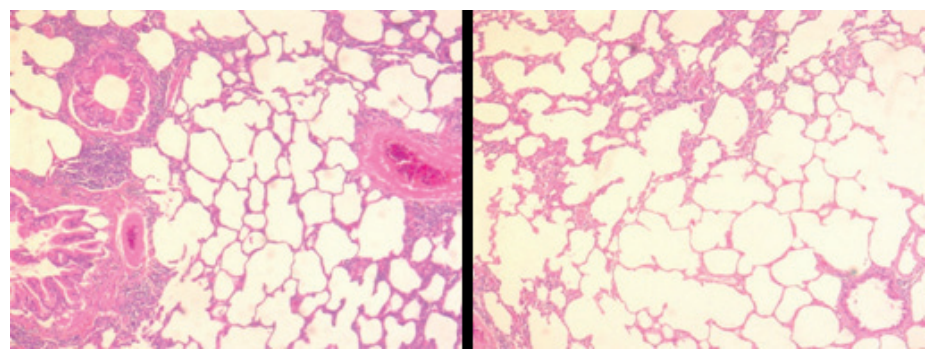

FIGURE 3 - Lung histopathological aspect of control group (right) with low parenchymal infiltration and absence of necrosis and thrombosis. The experimental group (left) presents high inflammatory cells and emphysematous changes (HE x10).

\section{Discussion}

Smoking is a serious public health problem worldwide. Many diseases are triggered by tobacco exposure, like cardiovascular and lung disorders with a natural history characterized by progressive and destructive lesions ${ }^{10,11}$. Unfortunately, nonsmokers are also submitted for these effects by exposure to ETS, with a great amount of toxic products that are harmful for different tissues in the organism ${ }^{12,13}$

Animal models are used as an intermediate step between laboratory studies and trials in human. There are different experimental models of exposure to ETS that uses different apparatus and varied methods of biochemical and histopathological analysis to authenticate the method ${ }^{5,6}$. 
The beginning of studies about experimental models of smoke really started in 1965, with the creation of Hamburg Smoking Machine, that is an automatic smoking machine for simultaneous smoking of 15 cigarettes at a time by vacuum cigarette holders producing puffs of smoke inside of an inhalation chamber ${ }^{14}$. After this event, many others machines were designed, using complex and automatic systems that needs of more vigilance in the use and difficulty in handling, with the capacity of 30 automatically operated vacuum cigarette holders that permit a puff of $35 \mathrm{ml}$ in volume (Hamburg II smoking machine) $)^{15}$.

This study suggests a new method of experimental exposure to ETS using easy materials that includes a simple aquarium pump (air compressor), catheters of saline infusion (conduction pipe) and a recipient for food storage (inhalation chambers). All these materials are very inexpensive and accessible in anywhere in the world, from the smaller to bigger centers of research.

The nicotine in cigarette smoke is inhaled and metabolized in the liver, producing cotinine, which is detectable in plasma Nicotine is a great harmful component in the cigarette, with destructive and malignant consequences ${ }^{7,16}$. The results show the significant difference in serum levels of Nicotine between the experimental and control group that prove the validity of the method of inhalation. Data from all histopathological examinations are presented in Table 1. Experimental Group (exposed to tobacco smoke) differed from Control Group in all the histopathological parameters. The alveolar destruction and emphysema revels the efficacy of the experimental model to produce lung injury by acute exposure to tobacco smoke ${ }^{6}$.

The individual inhalation chambers used in this study has a cylindrical shape to promote a homogeneous manner to smoke exposure, with a cover with holes to simulate an exposure on indoor places (like nightclubs and pubs) without asphyxia of the animals. Other studies have described chambers with the rats housed inside the chamber as a group during the inhalation. The bias of this manner of exposure can be understood by the behavior of the rats with the tendency to form groups, so not all of them received the same amount of smoke $\mathrm{e}^{7,17}$.

Different studies shown another problem that is products derived from tobacco are deposited on animal's skin. When animals lick themselves they ingest these cigarette components which modify the exposure information. Because of that, this the authors designed a "compartment of ash storage", that allows the smoke escape but do not permit the passage of the cigarette components $^{6,17}$.

The disadvantages of the system was a need to be performed in a airy place and researchers must use masks to minimize the passive smoke, furthermore, there is no way to standardize the amount of smoke breathed by the animals may not occur homogenization of the groups, depending on the weight of the animals, suger that to avoid this bias are used animals weighing approx.

\section{Conclusion}

The model of exposure to environmental tobacco smoke for rodents induced easily the changes related to secondhand smoke. Moreover, it presents low cost and easy preparation, allowing its development in any laboratory.

\section{References}

1. Glantz SA, Parmley WW. Passive smoking and heart disease: Epidemiology, physiology, and biochemistry. Circulation. 1991;83:1-12.

2. Jha P, Ramasundarahettige C, Landsman V, Rostron B, Thun M, Anderson RN, McAfee T, Peto R. 21st-century hazards of smoking and benefits of cessation in the United States. N Engl J Med. 2013;368:341-50.

3. Panda K. Vitamin C prevents cigarette smoke-induced oxidative damage of proteins and increased proteolysis. Free Radic Biol Med. 1999;27:1064-79.

4. Martini DZ, Mack JM, Linares CEB, Bolzan RC. Efeito da exposição à fumaça do cigarro sobre parâmetros comportamentais e peroxidação lipídica em camundongos. Rev Cienc Med Biol. 2010;9(3): 229-34.

5. Reid LM. Needs for animal models of human diseases of the respiratory system. Am J Pathol. 1980;101:89-101.

6. Mahadeva F, Shapiro SD. Chronic obstructive pulmonary disease: experimental animal models of pulmonary emphysema. Thorax. 2002;57:908-14.

7. Jardim JR, Bizeto L, Mayer AF, Camelier A, Rosa FW, Oliveira D, Azevedo D, Saldiva PH, Martins MA, Bonassa J, Nascimento AO. An inhalation chamber model for controlled studies of tobacco smoke toxicity in rodents. Arch Broncopneumol. 2010;46(9):455-8.

8. Brito MVH, Brito NMB, Almeida AJB, Santos MRLC. Vaporizador artesanal de éter para cirurgia experimental em pequenos roedores. Acta Cir Bras. 1998;13(1):3-7.

9. Dogan OT, Elagoz S, Ozsahin SL, Epozturk K, Tuncer E, Akkurt I. Pulmonary toxicity of chronic exposure to tobaccoand biomass smoke in rats. Clinics. 2011;66(6):1081-7.

10. Rabe KF, Hurd S, Anzueto A, Barnes PJ, Buist SA, Calverley P, Fukuchi Y, Jenkins C, Rodriguez-Roisin R, Van Weel C, Zielinski J. Global strategy for the diagnosis, management, and prevention of chronic obstructive pulmonary disease: GOLD executive summary. Am J Respir Crit Care. 2007;176:532-55.

11. Beard E, Aveyard P, Michie S, McNeill A, West R. Does use of nicotine replacement therapy while continuing to smoke undermine cessation? A systematic review. J Smok Cessat. 2013;8(1):45-56.

12. Nelson E. The miseries of passive smoking. Hum Exp Toxicol. 2001;20(2):61-83.

13. Jaakkola MS, Jaakkola JJ. Adverse health effects of passive smoking. Duodecim. 2012;128(10):1097-106. 
14. Klimisch HJ, Dontenwill W. Investigations of cigarette smoke dosages in inhalation experiments with syrian hamsters. I. concentration of cigarette smoke in the inhalation of cigarette smoke in the inhalation chamber and of carbon monoxide in the blood. J Natl Cancer Inst. 1976;58(4):931-3.

15. Mordelet-Dambrine M, Leguern-Stanislas G, Chinet TC, Barritault L, Chrétien J, Huchon GJ. Effects of tobacco smoke on respiratory epithelial clearance of DTPA and on lung histology in rats. Eur Respir J. 1991;4:839-44.

16. Nemmar A, Raza H, Subramaniyan D, Yasin J, John A, Ali BH, Kazzam EE. Short-term systemic effects of nose-only cigarette smoke exposure in mice: role of oxidative stress. Cell Physiol Biochem. 2013;31:15-24

17. Silva JB, Gazzalle A, Mano LFM, Cocolichio F, Zampieri JT, Pellizzari AC. É possível validar estatisticamente um dispositivo experimental com 10 ratos, de baixo custo, para pesquisa em tabagismo passivo? Rev Bras Cir Plast. 2011;26(2):194-7

\section{Correspondence:}

Marcus Vinicius Henriques Brito

Rua Apinagés, 630/202

66.033-170 Belém - PA Brasil

Tel.: (55 91)3222-9752/8854-8895

marcusvhbrito@gmail.com

Received: Aug 20, 2013

Review: Oct 18, 2013

Accepted: Nov 18, 2013

Conflict of interest: none

Financial source: Institutional Program for Scientific Initiation Scholarship (PIBIC), National Council for Scientific and Technological Development (CNPq)

${ }^{1}$ Research performed at Experimental Surgery Laboratory. School of Medicine, State University of Para (UEPA), Belem-PA, Brazil. 